\section{Memory span: Effects of symbol orientation}

\author{
BAYLA MILLER MYER and DANIEL C. O'CONNELL \\ Saint Louis University, St. Louis, Mo. 63103
}

Memory span for symbol strings was tested in a repeated measures design. Strings were nine symbols in length, with varying compositions (two to nine different symbols per string). Condition $\mathrm{C}$ had symbols in constant conventional orientation, Condition $\mathrm{A}$, in constant altered orientation, and Condition $\mathrm{V}$, variably in all 90-deg orientations. Memory span decreased as number of different symbols composing strings increased. Errors in recall showed that perceptual overlap of symbol features accounted for confusion. When symbols were rotated ( $V$ ), confusions became within-symbol rather than between-symbol; if orientation was ignored in $V$ and identity and position became the criteria for correctness, errors decreased even though symbols increased, and errors were due less systematically to perceptual mechanisms. Rotation disrupted between-symbol chunking.

This experiment examined a perceptual learning mechanism referred to as "chunking" that was responsible for results of a prior study (Myer \& O'Connell, 1972) in which errors in perception occurred because many stimulus features were embodied in complex symbols, viz, cross, slash, and upside-down $T$ in the asterisk, triangle in the diamond, and semicircle in the circle. Hence, in order to study how Ss associate and chunk features of symbol stimuli, three conditions of strings were introduced in a memory span task. Condition $C$ symbols were represented in conventional orientation in all strings (constant conventional condition). Condition A had symbols in a constant orientation but altered from conventional by a 90-deg clockwise rotation. Condition V used all possible 90-deg rotations.

Through Conditions $C, A$, and V, there is a progressive increase in attention the learner must give to the pool of perceptual symbol features. In $C$, symbols with available verbal labels composed the population. In $A$, five were in altered nonconventional orientation; asterisk, circle, square, and cross were not alterable by $90-\mathrm{deg}$ rotation and were the same in all conditions. It was hypothesized that Ss would attend more to perceptual features since verbal labels were less available for effective coding. In $V$, the symbol pool was increased to 20 and perceptual mechanisms bore the increased burden of discriminating within-symbol rotations. In $\mathrm{V}$, feature learning should occur (Gibson \& Gibson, 1955) because Ss attend to varyi $\lrcorner g$ symbols, learn distinctive features of the symbol, and improve in symbol discrimination. The perceptual chunking in $\mathrm{V}$ was hypothesized to be within-symbol-variation of orientation throughout the list of strings would force organization within symbol variations. Constant orientation, as in C (Myer \& O'Connell, 1972) and $A$, does not Condition errors and feature learning are inversely related, and that memory span is directly related to verbal codability of the symbol.

Twelve Ss were tested in each condition. In each condition, eight string compositions represented strings that were nine symbols in length; any particular string could be composed of $2,3,4,5,6,7,8$, or 9 different symbols. Eight strings of each composition were used to insure that symbol combinations were well represented. The analysis of variance model was Experimental Condition (C,A,V) by String Composition (two to nine different symbols) by String Trials (eight repetitions of each composition): an $\mathrm{A}$ by $\mathrm{B}$ by $\mathrm{C}$ factorial design with eight repeated measures on $\mathrm{B}$ and $\mathrm{C}$ factors.

\section{SYMBOL STRINGS AND LISTS}

The nine symbols from Myer \& O'Connell (1972) were used. In Condition $\mathrm{C}$, the nine symbols were each represented always in their conventional orientation, as in Table 1. In Condition A, the nine symbols were each represented always in their conventional orientation altered by a 90-deg clockwise rotation; functionally, only five symbols were reoriented, since a $90-\mathrm{deg}$ rotation clockwise does not alter the asterisk, circle, square, or cross. In Condition $V$, the nine symbols were variously represented in all possible 90-deg rotations with equal frequency. Twenty symbols resulted in the Condition V pool: asterisk, circle, square, and cross were unchanged by any $90-\mathrm{deg}$ reorientation (four symbols); semicircle, upside-down $\mathrm{T}$, and triangle each appeared in four different orientations $(0,90,180$, and

Table 1

Representations of the Symbols Composing Strings in Each Experimental Condition Symbols and Their Code Numbers

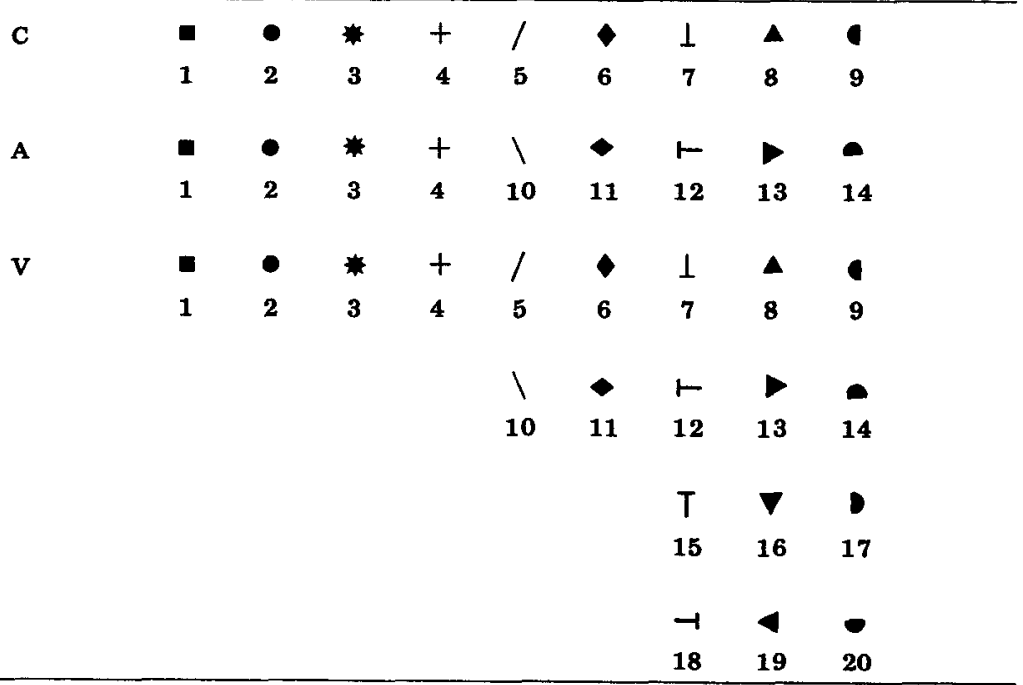


270 deg) and added 12 symbols to the Condition V pool; diamond and slash appeared in two different orientations (0 deg was identical to $180 \mathrm{deg} ; 90 \mathrm{deg}$ was identical to $270 \mathrm{deg}$ ) and added four symbols, for a total of 20 symbols in the Condition V symbol pool. All strings were nine symbols in length, and each symbol was centered in one of nine horizontally adjacent $10-\mathrm{sq} \mathrm{cm}$ areas. Lists for each condition contained 64 strings plus 5 introductory practice strings. The 64 strings were eight repetitions from eight compositions.

Eight groups of sy mbol combinations were picked randomly for each of the eight compositions with two constraints: No repetition of any combination (except for Composition 8 for which there was only one combination possible, since all symbols were always used in a string nine symbols long requiring nine different symbols) and all symbols were used before any symbol already used in a combination was repeated. Orderings of symbols within strings were determined randomly from the symbol combi ,ations, with each symbol occurring before any symbol was repeated again. Irrespective of rotational differences within the strings, the 64 strings and their order were the same for the $C, A$, and $V$ lists; in $V$ strings, to insure equal occurrences of all orientations, symbol orientation was varied randomly with one constraint: each orientation had to occur before any orientation occurred again. The order of the 64 strings in the lists was random, with one constraint: a string from each of the eight compositions occurred before any string repeated a composition.

\section{PROCEDURE}

Apparatus consisted of a Stowe memory drum and three lists. The Ss were seated $15 \mathrm{in}$. from the drum window. Instructions for ordered recall were read by $S$, and data sheets were provided with 69 sets of nine blank adjacent boxes (each $10 \times 10 \mathrm{~cm}$ ). Strings were presented sequentially, one at a time, for $3 \mathrm{sec}$, and $S$ had 12 sec to record recall. A mirror was used by $\mathrm{E}$ to insure that recall was not commenced until each string disappeared from view.

$$
\text { SUBJECTS }
$$

Thirty-six undergraduates voluntarily served as Ss. All were enrolled in psychology courses at St. Louis University and were not necessarily naive to memory studies. Ss were individually assigned to a condition by use of a running order containing 12 blocks; each block contained a single $S$ from each condition and was filled before the subsequent block was initiated.

\section{RESULTS AND DISCUSSION OF ERRORS}

Refer to Table 2 for the complete matrix of errors.

\section{Condition $\mathrm{C}$}

The asterisk was misrepresented with disproportionate frequency as cross, slash, or $T$, all of which are embodied in the asterisk as features so that chunking would account for the errors. The cross had disproportionate errors as slash, $\mathrm{T}$, and asterisk, all sharing common features apt for chunking. Errors involving the slash were mostly accounted for by the asterisk, cross, and T. These symbols apparently form a pool of perceptual features out of which $\mathbf{S}$ draws when forced to decide which symbol occurred. Only when the pool consists of a single symbol could it be predicted that between-symbol errors would not be systematic. Diamonds were incorrectly recalled most often as triangles, and vice versa. This had been predicted, since a triangle is a perceptual feature of the diamond. Semicircles were mostly confused with circles and both would occupy the same pool of features. Perceptual overlap of features is empirically supported as a source of errors. Condition A

The errors due to the intruding representation of diamonds and triangles in unaltered conventional orientation indicated that rotated symbols in Condition $A$ went against the perceptual grain of encoded overlearned conventional orientation. Slash errors also were mostly slashes in conventional orientation. What was to occur explicitly in Condition $V$ was implicitly occurring in Condition $\mathrm{A}$ : Ss create within-symbol feature pools and thereby restrict errors to within-symbol orientations. If within-symbol errors are ignored, fewer errors occur in Condition $A$ than in Condition $\mathrm{C}$, apparently due to implicit enlargement of the within-symbol feature pool. In Condition $\mathrm{C}, \mathrm{S}$ can use a larger segment of storage capacity for between-symbol connections; by presenting $\mathbf{S}$ with an explicitly altered orientation-under the assumption that the implicit, more conventional orientation is taking up storage space-a larger part of the limited information load is filled.

There were more total errors in Condition $A(1,046)$ than in Condition C (800). Whether the correct symbol in an incorrect orientation is recorded as an error is of theoretical import. Identity and position must be scored strictly, but orientation can be disregarded. This scoring method is referred to as loose (L), whereas the method that required correct rotation was strict (S). The scoring modification is justifiable insofar as the instructions did not suggest that symbol orientation was a relevant aspect of the task; Ss were requested only to get symbol identification and location correct. The $\mathrm{L}$ scoring partialed out errors in which the correct symbol was recorded in an incorrect orientation. In $A$, errors are thus reduced by 231 due to correct identification of a symbol in an intruding orientation. Errors in $\mathbf{A}$ are accordingly reduced to 815 , not appreciably more than in $\mathrm{C}$ (800).

The circle was misrepresented mostly as a semicircle. Rotating the semicircle fostered the circle-semicircle relationship as predicted, although storage capacity for the circle itself was no more loaded than in Conditions $\mathrm{C}$ and $\mathrm{A}$. Whereas circles accounted for the majority of semicircle errors in $C$ and $A$, it was confirmed that within-symbol semicircle substitutions would occur in $\mathrm{V}$ and the between-symbol association of circle and semicircle was weakened. The $T$, slash, cross, and asterisk also underwent a reduction in strength of the relationship due to loading the channels of varying symbols ( $T$, slash) with within-symbol information. The slash provides further evidence that rotated orientation primes within-symbol feature learning and inhibits between-symbol confusion. Forcing perceptual feature learning within symbols yields a decrease in between-symbol confusions. Triangle errors were significantly reduced by discounting within-triangle orientation errors. Orientation yields evidence that between-symbol associations are inhibited by buildup of within-symbol associations. Of the triangle errors in $\mathrm{V}, \mathbf{2 4 . 4 \%}$ were diamonds; in $\mathrm{C}, 50.5 \%$ were diamonds; and in $\mathrm{A}, 27.4 \%$ were diamonds. It is clear that the triangle-diamond relationship is weakened by varying (V) or altering (A) orientation. The latter allows Ss implicitly to strengthen within-symbol associations with the more conventional orientation, while the former explicitly presents the within-symbol information.

\section{RESULTS AND DISCUSSION} OF MEMORY SPAN

Results from Conditions C, A, and $V$ under $S$ and $L$ scoring are shown in Fig. 1. A conservative $F$ test was used on the untransformed data $(d f=1, n)$, since a repeated measures design was employed (Winer, 1971).

As number of different symbols/string increased, memory span decreased. The conventionally oriented group (C) is the same whether loosely (CL) or strictly (CS) scored; this complete overlap between the two 
Table 2

\begin{tabular}{|c|c|c|c|c|c|c|c|c|c|c|c|c|c|c|c|c|c|c|c|c|c|c|}
\hline & \multirow[b]{2}{*}{ Symbols* } & \multirow{2}{*}{$\begin{array}{c}\text { Total } \\
\text { Errors } \\
\end{array}$} & \multicolumn{20}{|c|}{ Misrepresentation Error Percentages } \\
\hline & & & 1 & 2 & 3 & 4 & 5 & 6 & 7 & 8 & 9 & 10 & 11 & 12 & 13 & 14 & $\mathbf{1 5}$ & 16 & 17 & 18 & 19 & 20 \\
\hline Condition $\mathbf{C}$ & $\begin{array}{l}1 \\
2 \\
3 \\
4 \\
5 \\
6 \\
7 \\
8 \\
9\end{array}$ & $\begin{array}{r}55 \\
59 \\
65 \\
132 \\
86 \\
88 \\
90 \\
113 \\
112\end{array}$ & $\begin{array}{r}16.9 \\
4.6 \\
11.4 \\
10.5 \\
11.4 \\
5.5 \\
13.3 \\
10.7\end{array}$ & $\begin{array}{r}14.5 \\
\\
6.2 \\
3.0 \\
10.5 \\
7.9 \\
10.0 \\
3.5 \\
42.0\end{array}$ & $\begin{array}{r}10.9 \\
11.9 \\
\\
31.8 \\
20.9 \\
3.4 \\
8.9 \\
4.4 \\
10.7\end{array}$ & $\begin{array}{r}14.5 \\
8.5 \\
21.5 \\
19.8 \\
2.3 \\
33.3 \\
6.2 \\
6.2\end{array}$ & $\begin{array}{r}14.5 \\
18.6 \\
26.2 \\
15.9 \\
\\
7.9 \\
30.0 \\
5.3 \\
7.1\end{array}$ & $\begin{array}{l}\mathbf{0} \\
\mathbf{0} \\
\mathbf{0} \\
\mathbf{0} \\
\mathbf{0} \\
\mathbf{0} \\
\mathbf{0} \\
\mathbf{0} \\
\mathbf{0}\end{array}$ & $\begin{array}{r}12.7 \\
10.2 \\
3.1 \\
2.3 \\
10.5 \\
\\
5.5 \\
50.4 \\
5.4\end{array}$ & $\begin{array}{l}\mathbf{0} \\
0 \\
0 \\
0 \\
0 \\
0 \\
0 \\
0 \\
0\end{array}$ & $\begin{array}{r}9.1 \\
13.6 \\
23.1 \\
27.3 \\
17.4 \\
3.4 \\
\\
3.5 \\
7.1\end{array}$ & $\begin{array}{l}0 \\
0 \\
0 \\
0 \\
0 \\
0 \\
0 \\
0 \\
0\end{array}$ & $\begin{array}{l}0 \\
0 \\
0 \\
0.8 \\
0 \\
0 \\
0 \\
0 \\
0\end{array}$ & $\begin{array}{l}0 \\
0 \\
0 \\
0 \\
0 \\
0 \\
0 \\
0 \\
0\end{array}$ & $\begin{array}{r}16.4 \\
10.2 \\
6.2 \\
5.3 \\
2.3 \\
60.2 \\
2.2\end{array}$ & $\begin{array}{l}\mathbf{0} \\
\mathbf{0} \\
\mathbf{0} \\
\mathbf{0} \\
\mathbf{0} \\
\mathbf{0} \\
\mathbf{0} \\
\mathbf{0} \\
\mathbf{0}\end{array}$ & $\begin{array}{l}0 \\
0 \\
0 \\
0 \\
0 \\
0 \\
0 \\
0 \\
0\end{array}$ & $\begin{array}{l}0 \\
0 \\
0 \\
0 \\
0 \\
0 \\
0 \\
0 \\
0\end{array}$ & $\begin{array}{r}7.3 \\
10.2 \\
7.7 \\
2.3 \\
8.1 \\
3.4 \\
2.2 \\
8.0\end{array}$ & $\begin{array}{l}0 \\
0 \\
0 \\
0 \\
0 \\
0 \\
0 \\
0 \\
0\end{array}$ & $\begin{array}{l}0 \\
0 \\
1.5 \\
0 \\
0 \\
0 \\
2.2 \\
5.3 \\
0\end{array}$ & $\begin{array}{l}0 \\
0 \\
0 \\
0 \\
0 \\
0 \\
0 \\
0 \\
0\end{array}$ \\
\hline Condition A & $\begin{array}{r}1 \\
2 \\
3 \\
4 \\
10 \\
11 \\
12 \\
13 \\
14\end{array}$ & $\begin{array}{r}62 \\
77 \\
53 \\
143 \\
122 \\
230 \\
96 \\
157 \\
106\end{array}$ & $\begin{array}{r}16.9 \\
3.8 \\
8.4 \\
7.4 \\
6.5 \\
6.3 \\
12.1 \\
2.8\end{array}$ & $\begin{array}{r}21.0 \\
17.0 \\
9.1 \\
18.9 \\
7.4 \\
11.5 \\
7.0 \\
34.9\end{array}$ & $\begin{array}{r}3.2 \\
16.9 \\
\\
29.4 \\
8.2 \\
1.7 \\
4.2 \\
2.5 \\
11.3\end{array}$ & $\begin{array}{r}8.2 \\
2.2 \\
26.0 \\
6.4 \\
7.5\end{array}$ & $\begin{array}{r}\mathbf{3 . 2} \\
3.9 \\
3.8 \\
5.6 \\
\mathbf{3 6 . 9} \\
1.3 \\
\mathbf{5 . 2} \\
\mathbf{1 . 9} \\
0\end{array}$ & $\begin{array}{r}9.7 \\
20.8 \\
13.2 \\
7.0 \\
\\
2.2 \\
16.7 \\
3.8 \\
8.5\end{array}$ & $\begin{array}{r}17.7 \\
3.9 \\
3.8 \\
1.4 \\
0 \\
04.3 \\
3.1 \\
16.6 \\
4.7\end{array}$ & $\begin{array}{l}\mathbf{0} \\
\mathbf{0} \\
\mathbf{0} \\
\mathbf{0} \\
\mathbf{0} \\
\\
\mathbf{0} \\
\mathbf{0} \\
\mathbf{0}\end{array}$ & $\begin{array}{l}0 \\
0 \\
0 \\
0 \\
0 \\
0 \\
3.1 \\
0 \\
0\end{array}$ & $\begin{array}{r}1.6 \\
5.2 \\
13.2 \\
20.3 \\
4.1 \\
2.2 \\
\\
4.5 \\
8.5\end{array}$ & $\begin{array}{c}1.6 \\
1.3 \\
5.7 \\
11.9 \\
1.6 \\
0 \\
12.5 \\
0 \\
0.9\end{array}$ & $\begin{array}{l}0 \\
0 \\
1.9 \\
0 \\
0.8 \\
0 \\
0 \\
0 \\
0\end{array}$ & $\begin{array}{r}14.5 \\
5.2 \\
1.9 \\
2.1 \\
4.9 \\
24.8 \\
5.2 \\
39.5 \\
8.5\end{array}$ & $\begin{array}{c}16.1 \\
0 \\
3.8 \\
0.7 \\
0 \\
5.7 \\
0\end{array}$ & $\begin{array}{l}0 \\
0 \\
0 \\
0 \\
0 \\
0 \\
0 \\
0 \\
0\end{array}$ & $\begin{array}{l}1.6 \\
0 \\
0 \\
0 \\
0 \\
0.9 \\
0 \\
0 \\
0\end{array}$ & $\begin{array}{l}0 \\
0 \\
0 \\
0 \\
0 \\
0 \\
0 \\
0 \\
0\end{array}$ & $\begin{array}{r}3.2 \\
16.9 \\
18.9 \\
2.8 \\
4.1 \\
0.9 \\
6.3 \\
1.9\end{array}$ & $\begin{array}{l}0 \\
2.6 \\
0 \\
1.4 \\
4.9 \\
0 \\
0 \\
3.8 \\
6.6\end{array}$ & $\begin{array}{l}0 \\
0 \\
0 \\
0 \\
0 \\
0 \\
0 \\
0 \\
0\end{array}$ \\
\hline Condition $\mathrm{V}$ & $\begin{array}{r}1 \\
2 \\
3 \\
4 \\
5 \\
6 \\
7 \\
8 \\
9 \\
10 \\
11 \\
12 \\
13 \\
14 \\
15 \\
16 \\
17 \\
18 \\
19 \\
20\end{array}$ & $\begin{array}{r}48 \\
64 \\
57 \\
120 \\
57 \\
69 \\
38 \\
140 \\
31 \\
48 \\
27 \\
25 \\
33 \\
65 \\
43 \\
58 \\
51 \\
69 \\
48 \\
27\end{array}$ & $\begin{array}{r}18.8 \\
3.5 \\
10.0 \\
10.5 \\
8.7 \\
5.3 \\
2.1 \\
0 \\
2.1 \\
3.7 \\
4.0 \\
6.0 \\
4.6 \\
4.7 \\
5.2 \\
2.0 \\
5.8 \\
0 \\
0\end{array}$ & $\begin{array}{r}25.0 \\
\\
19.3 \\
7.5 \\
8.8 \\
4.3 \\
7.9 \\
4.3 \\
12.9 \\
4.2 \\
7.4 \\
8.0 \\
15.1 \\
0 \\
9.3 \\
5.2 \\
9.8 \\
13.0 \\
12.5 \\
14.8\end{array}$ & $\begin{array}{r}8.3 \\
6.3 \\
\\
20.0 \\
12.3 \\
14.5 \\
10.5 \\
2.9 \\
3.2 \\
0 \\
7.4 \\
8.0 \\
6.0 \\
0 \\
4.7 \\
1.7 \\
3.9 \\
11.6 \\
6.3 \\
11.1\end{array}$ & $\begin{array}{c}16.7 \\
4.7 \\
12.3 \\
\\
7.0 \\
0 \\
0 \\
0 \\
12.9 \\
4.2 \\
7.4 \\
12.0 \\
9.1 \\
0 \\
4.7 \\
1.7 \\
0 \\
0 \\
0 \\
7.4\end{array}$ & $\begin{array}{r}12.5 \\
12.5 \\
22.8 \\
9.2 \\
\\
53.6 \\
2.6 \\
1.4 \\
0 \\
2.1 \\
11.1 \\
0 \\
0 \\
1.5 \\
0 \\
1.7 \\
2.0 \\
4.3 \\
2.1 \\
3.7\end{array}$ & $\begin{array}{r}12.5 \\
6.3 \\
5.3 \\
0.8 \\
52.6 \\
\\
5.3 \\
0 \\
0 \\
4.2 \\
0 \\
4.0 \\
0 \\
3.1 \\
0 \\
0 \\
0 \\
2.9 \\
0 \\
3.7\end{array}$ & $\begin{array}{l}0 \\
1.6 \\
1.7 \\
1.7 \\
0 \\
0 \\
\\
58.6 \\
0 \\
2.1 \\
0 \\
0 \\
12.1 \\
3.1 \\
9.3 \\
6.9 \\
0 \\
0 \\
0 \\
3.7\end{array}$ & $\begin{array}{l}0 \\
0 \\
0 \\
0 \\
0 \\
0 \\
31.6 \\
\\
0 \\
0 \\
3.7 \\
0 \\
0 \\
1.5 \\
4.7 \\
1.7 \\
0 \\
0 \\
0 \\
0\end{array}$ & $\begin{array}{l}0 \\
1.6 \\
3.5 \\
7.5 \\
0 \\
2.9 \\
2.6 \\
1.4 \\
\\
2.1 \\
7.4 \\
24.0 \\
0 \\
0 \\
2.3 \\
0 \\
2.0 \\
0 \\
4.2 \\
0\end{array}$ & $\begin{array}{l}2.1 \\
0 \\
0 \\
0.8 \\
0 \\
0 \\
0 \\
0 \\
9.7 \\
\\
22.2 \\
4.0 \\
0 \\
0 \\
0 \\
0 \\
0 \\
1.4 \\
2.1 \\
0\end{array}$ & $\begin{array}{c}4.2 \\
6.3 \\
10.5 \\
34.2 \\
3.5 \\
5.8 \\
0 \\
0.7 \\
48.4 \\
75.0 \\
\\
32.0 \\
3.0 \\
0 \\
0 \\
0 \\
0 \\
2.9 \\
6.3 \\
0\end{array}$ & $\begin{array}{l}0 \\
0 \\
1.7 \\
0 \\
1.7 \\
0 \\
0 \\
0 \\
3.2 \\
2.1 \\
18.5 \\
\\
0 \\
0 \\
0 \\
0 \\
0 \\
2.9 \\
0 \\
0\end{array}$ & $\begin{array}{c}6.3 \\
6.3 \\
5.3 \\
3.3 \\
3.5 \\
4.3 \\
28.9 \\
17.1 \\
9.7 \\
0 \\
0 \\
4.0 \\
\\
41.5 \\
30.2 \\
58.6 \\
2.0 \\
1.4 \\
2.1 \\
0\end{array}$ & $\begin{array}{l}2.1 \\
1.6 \\
0 \\
0.8 \\
0 \\
0 \\
2.6 \\
2.9 \\
0 \\
0 \\
0 \\
0 \\
27.3 \\
\\
18.6 \\
12.1 \\
0 \\
0 \\
0 \\
0\end{array}$ & $\begin{array}{l}2.1 \\
1.6 \\
0 \\
0 \\
0 \\
0 \\
0 \\
2.1 \\
0 \\
0 \\
0 \\
0 \\
6.0 \\
23.1 \\
\\
3.4 \\
0 \\
0 \\
0 \\
3.7\end{array}$ & $\begin{array}{l}2.1 \\
0 \\
3.5 \\
0.8 \\
0 \\
0 \\
0 \\
2.9 \\
0 \\
0 \\
0 \\
0 \\
15.1 \\
16.9 \\
4.7 \\
\\
2.0 \\
0 \\
0 \\
0\end{array}$ & $\begin{array}{l}2.1 \\
4.7 \\
5.3 \\
0 \\
0 \\
2.9 \\
0 \\
0 \\
0 \\
0 \\
7.4 \\
0 \\
0 \\
0 \\
0 \\
1.7 \\
\\
14.5 \\
29.2 \\
29.6\end{array}$ & $\begin{array}{l}0 \\
10.9 \\
0 \\
0 \\
0 \\
0 \\
0 \\
0.7 \\
0 \\
2.1 \\
0 \\
0 \\
0 \\
0 \\
2.3 \\
0 \\
13.7 \\
16.7 \\
0\end{array}$ & $\begin{array}{c}4.2 \\
15.6 \\
3.5 \\
0.8 \\
0 \\
0 \\
2.6 \\
1.4 \\
0 \\
0 \\
3.7 \\
0 \\
0 \\
4.6 \\
4.7 \\
0 \\
43.1 \\
14.5 \\
\\
22.2\end{array}$ & $\begin{array}{l}0 \\
1.6 \\
1.7 \\
2.5 \\
0 \\
2.9 \\
0 \\
1.4 \\
0 \\
0 \\
0 \\
0 \\
0 \\
0 \\
0 \\
0 \\
19.6 \\
24.6 \\
18.7\end{array}$ \\
\hline
\end{tabular}




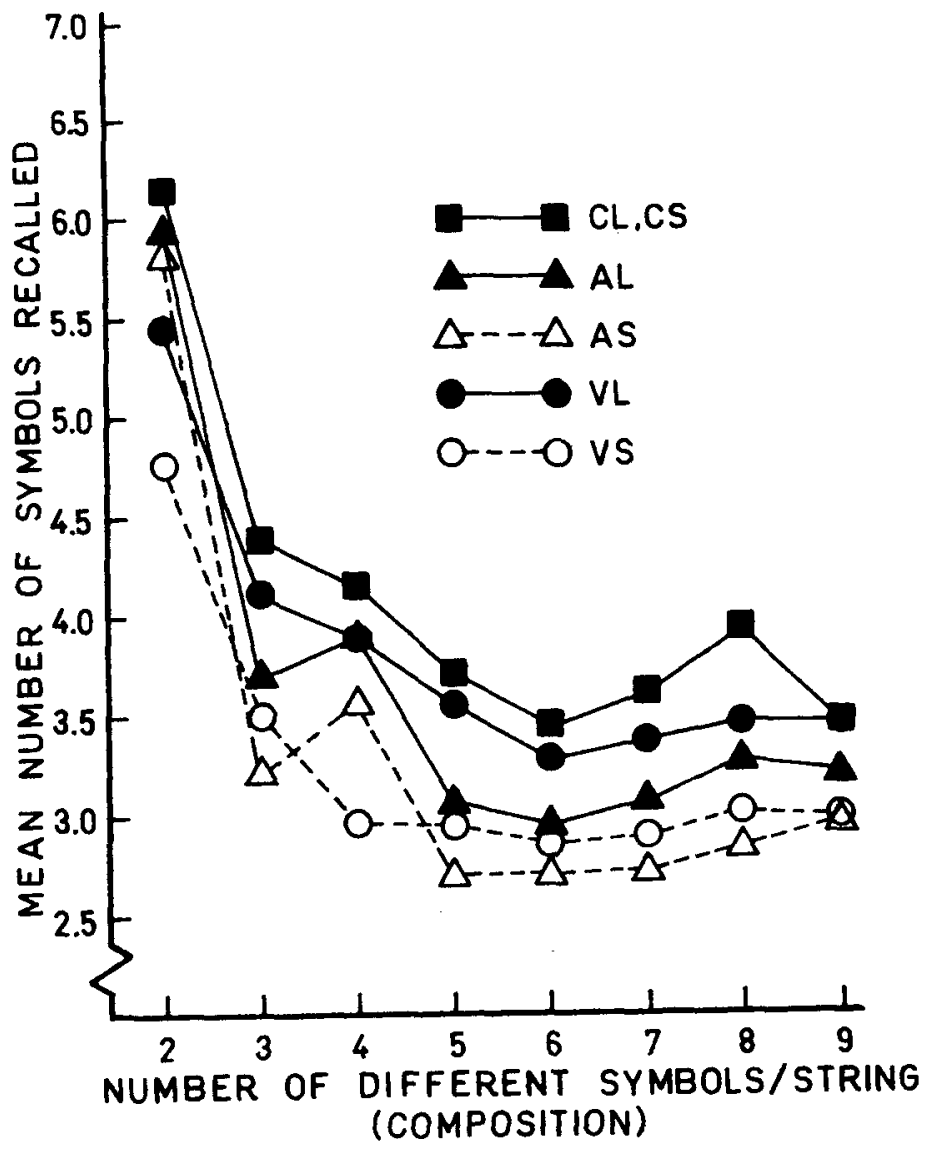

Fig. 1. Strict (S) and loose (L) scoring of memory span in Conditions C, A, and $\mathrm{V}$.

scoring methods supports the choice of correct conventional orientations since there were no intrusions of less common orientations.

Another point is made empirically in Fig. 1: Symbol memory span does not approach the magical number seven. These results agree with Myer \& O'Connell (1972) and Ross (1969). The 5 by 8 by 8 analysis of variance showed a significant main effect of the condition, $\mathrm{F}(1,5)=4.76, \mathrm{p}<.05$. The main effect of string composition was clearly significant, $F(1,8)=176.92$, $\mathrm{p}<.001$. Myer \& O'Connell (1972) showed significant main effects of string composition also, with recall decreasing as number of different symbols per string increases.

Figure 1 shows that memory was best in Condition $\mathrm{C}$, and VL most closely approximates Condition $\mathrm{C}$. The results indicate that, with $\mathrm{L}$ scoring, $\mathrm{V}$ is superior to $A$ and closely approaches C.

The trials main effect was also significant, $F(1,8)=18.31, p<.001$, and the two-way Compositions by Trials interaction was significant, $F(1,64)=12.54, p<.05$. No other interaction effects were significant.

The perceptual learning mechanism underlying both errors and memory span in this experiment thus appears to be aptly expressed in terms of a feature analysis.

\section{REFERENCES}

GIBSON, J. J., \& GIBSON, E. J. Perceptual learning: Differentiation or enrichment? Psychological Review, 1955, 62, 32-41.

MYER, B M \& O'CONNELL, D. C Memory span: Effects of string length and string composition. Journal of Experimental Psychology, 1972, in press.

ROSS, B. M. Sequential visual memory and the limited magic of the number seven. Journal of Experimental Psychology, $1969,80,339-347$.

WINER, B. J. Statistical principles in experimental design. (2nd ed.) New York: MeGraw-Hill, 1971. 